\title{
Opium use during pregnancy and infant size at birth: a cohort study
}

\author{
Siavash Maghsoudlou ${ }^{1,2^{*}}$ (D), Sven Cnattingius ${ }^{1}$, Scott Montgomery ${ }^{1,3,4}$, Mohsen Aarabi ${ }^{5}$, Shahriar Semnani ${ }^{6}$, \\ Anna-Karin Wikström ${ }^{1,7}$ and Shahram Bahmanyar ${ }^{8}$
}

\begin{abstract}
Background: The reported positive association between opiatic drug use during pregnancy and adverse pregnancy outcomes might be confounded by other factors related to high-risk behaviors, including the use of other harmful substances. In rural areas of Iran, opium use during pregnancy is relatively common among women who otherwise do not have a hazardous lifestyle, which reduces the risk of residual confounding and increasing the possibility to identify its effects. We aimed to examine the association of antenatal exposure to opium with risks of small for gestational age, short birth length, and small head circumference at birth.
\end{abstract}

Method: In this cohort study in the rural area of the Golestan province, Iran, we randomly selected 920 women who were exposed to opium during pregnancy and 920 unexposed women during 2008-2010. Log-binomial regression was used to estimate risk ratios (RR) and 95\% confidence intervals (Cl) for the associations between prenatal exposure to opium and risks of small for gestational age, short birth length, and small head circumference at birth.

Results: Compared with non-use of opium and tobacco during pregnancy, using opium only and dual use of opium and tobacco were associated with increased risks of small for gestational age at births (RR $=1.71 ; 95 \% \mathrm{Cl} 1.34-2.18$ and $\mathrm{RR}=1.62 ; 95 \% \mathrm{Cl} 1.13-2.30$, respectively). Compared with non-use of opium and tobacco, exposure to only opium or dual use of opium and tobacco were also associated with more than doubled increased risks of short birth length, and small head circumference in term infants.

Conclusion: Maternal opium use during pregnancy is associated with increased risks of giving birth to a small for gestational age infant, as well as a term infant with short birth length or small head circumference.

Keywords: Birth size, Iran, Opium, Pregnancy, Small for gestational age

\section{Background}

There has been an epidemic of opioid abuse worldwide, including North America, UK, Australia, and Asian countries [1, 2]. Opium (Poppy tears, Lachryma Papaveris, Theriac) has traditionally been used in Middle-eastern and south Asian countries, such as Iran, Afghanistan, Pakistan, India, and China, even during pregnancy [3]. Opium obtained from the poppy plant, Papaver somniferous, contains morphine ( $10 \%$ of opium), Codeine $(0.5 \%)$, Thebaine $(0.2 \%)$, Papaverine (1\%), and Noscapine (6\%) [4].

\footnotetext{
* Correspondence: siavashmaghsoudlou@hotmail.com;

shahram.bahmanyar@ki.se

${ }^{1}$ Clinical Epidemiology Unit, Department of Medicine, Karolinska Institute, Solna, Sweden

${ }^{2}$ Department of Obstetrics \& Gynecology, McMaster University, 1280 Main

Street West, room 3N52F, Hamilton, ON L8S 4K1, Canada

Full list of author information is available at the end of the article
}

Use of opioids during pregnancy, including heroin and methadone, has been associated with adverse pregnancy outcomes, such as preterm delivery, low birth weight, SGA, and neonatal complications [5]. However, these studies were performed on drug addicts in high-income countries, and the reported effect of the opioid use on pregnancy outcomes might be confounded by social factors, lifestyle and other factors related to high-risk behaviors, including the use of other harmful substances [6]. Thus, differentiating the effects of opioid use from the effects of other risk factors has been difficult [7].

In Golestan province, northern Iran, some women use (mainly smoke) opium [8]. In this area, opium-using women are mostly homemakers, who otherwise do not have a hazardous lifestyle - such as homelessness and criminal behavior - which reduces the risk of residual

(C) The Author(s). 2018 Open Access This article is distributed under the terms of the Creative Commons Attribution 4.0 International License (http://creativecommons.org/licenses/by/4.0/), which permits unrestricted use, distribution, and 
confounding $[9,10]$. In a cohort study from north-east Iran, we used prospectively collected information before and during pregnancy to examine the association of antenatal exposure to opium with anthropometric characteristics of the newborn infants, including weight, length, and head circumference at birth.

\section{Methods}

A detailed description of the study population and method appears elsewhere [11]. Briefly, we performed a cohort study in rural areas of Golestan province, in northeast Iran, between 2008 and 2010. The province has approximately 1, 700, 000 inhabitants. Around 50\% are living in rural areas, where there are approximately 280, 000 women in reproductive age and 17, 000 births annually. Based on the national public health care system in Iran, each village has at least one rural health house, which is part of the primary health care organization and works under the authority of more specialized health care centers. The health houses are responsible for providing care and recording of health-related data, including medical information before and during pregnancy. Medical information including maternal drug use, cigarette smoking, alcohol use, and other high-risk behaviors are recorded both before and during pregnancy [9]. Opium is the most common drug in Golestan province and is usually smoked [12].

The exposed group included women with a self-reported history of using any of a variety of opiates during the index pregnancy. The unexposed group included women who did not use opium before or during pregnancy. We used the stratified random sampling method to select exposed and unexposed groups. Each of the 13 regions of the province was determined as a block, and the sample size of each block was estimated based on the population growth rate of the region. There were 30, 868 pregnancies during the study period. Exposed pregnancies were randomly selected, using computer-created random digits and the same number of women unexposed to opium during pregnancy were frequency-matched to the exposed women by the residential area (village). Information on pregnancies was abstracted from medical records and computerized. As a quality control, some $10 \%$ of the data was collected a second time. We recollected the data if there were more than $5 \%$ mismatches.

We selected a total of 920 opium users during pregnancy ("exposed" women) and 920 non-opium users ("unexposed" women). Thereafter, we excluded women with multiple births, miscarriages, and stillbirths, also women who gave up using opium in early pregnancy, used alcohol during pregnancy, and tobacco smokers among the unexposed group (15 unexposed and 33 exposed mothers). Finally, our study included 887 opium users (of whom 210 also smoked tobacco, and 677 only used opium) and 905 non-opium users with live singleton births.
Information on socioeconomic circumstances was based on the husband's profession (categorized as an unskilled manual worker, skilled manual worker, self-employed, farmer, other occupations, and unemployed). Agricultural production is the main economic sector in Golestan province. Gestational age was based on the time interval between the date of the first day of the last menstrual period and the date of delivery. Preterm delivery was defined as a delivery before 37 completed gestational weeks. Small for gestational age (SGA) was defined as a birth weight below the 10th percentile for gestational age, based on a sex-specific global reference for birth weight [13]. The 5th percentile of birth length (crown-heel length) and head (Occipito-Frontal) circumference among unexposed and term pregnancies were considered as cut-offs for short birth length (shorter than $47 \mathrm{~cm}$ ) and small head circumference (smaller than $33 \mathrm{~cm}$ ), respectively.

We used univariate and multivariate log-binomial regression models to estimate risk ratios (RRs) and 95\% confidence intervals (CIs) for the associations between opium use during pregnancy and SGA, short birth length, and small head circumference. The models were adjusted for potential confounding factors, including the region of residence, maternal age, parity, height, body mass index, husband's occupation, and infant sex. Due to scarce data on preterm infants, we could not construct gestationalage specific curves for birth length and head circumference. We restricted the analyses of birth length and head circumference to term births ( $\geq 37$ weeks), where we additionally also adjusted for gestational age (in weeks). Stratified analyses were performed to investigate the risks of SGA, short birth length, and small head circumference among opium-using mothers who smoked or did not smoke tobacco during pregnancy.

We used multiple imputation method with five imputations approach was used to provide data where there were missing values for maternal age (6 among mothers unexposed to opium and 5 among exposed mothers), infant sex (15 among mothers unexposed to opium and 10 among exposed mothers), husband's occupation (4 among unexposed and 9 among exposed), and mother's height (39 among unexposed and 17 among exposed). SAS software version 9.4 was used for all analyses.

\section{Results}

Table 1 shows maternal and births characteristics in unexposed, all exposed, exposed to opium only and exposed to both opium and tobacco. Among unexposed women, 28\% were 30 years or older, and 59\% were parous. For women exposed to opium corresponding figures were $44 \%$ and $78 \%$, respectively. There were no differences between the cohorts regarding other maternal characteristics. Among infants prenatally unexposed and exposed to opium, 6.5\% and $13.0 \%$ were shorter than $47 \mathrm{~cm}$ at birth, respectively, 
Table 1 Characteristics of study subjects

\begin{tabular}{|c|c|c|c|c|}
\hline & \multirow{3}{*}{$\begin{array}{l}\text { Unexposed }^{a} \\
N(\%)\end{array}$} & \multicolumn{3}{|c|}{ Opium user } \\
\hline & & All & Opium user only & Tobacco and Opium user \\
\hline & & $N(\%)$ & $N(\%)$ & $N(\%)$ \\
\hline \multicolumn{5}{|l|}{ Maternal age (Years) } \\
\hline$\leq 19$ & $134(14.8)$ & $49(5.5)$ & $40(5.9)$ & $9(4.3)$ \\
\hline $20-24$ & $250(27.6)$ & $161(18.2)$ & $133(19.6)$ & $28(13.3)$ \\
\hline $25-29$ & $260(28.7)$ & $278(31.3)$ & $210(31.0)$ & $68(32.4)$ \\
\hline $30-34$ & $187(20.7)$ & $251(28.3)$ & $181(26.7)$ & $70(33.3)$ \\
\hline$\geq 35$ & $68(7.5)$ & $143(16.1)$ & $108(16.0)$ & $35(16.7)$ \\
\hline Missing & $6(0.7)$ & $5(0.6)$ & $5(0.7)$ & $0(0)$ \\
\hline \multicolumn{5}{|l|}{ Parity } \\
\hline Nulliparous & $372(41.1)$ & $199(22.4)$ & $155(22.9)$ & $44(21.0)$ \\
\hline Parous & $533(58.9)$ & $688(77.6)$ & $522(77.1)$ & $169(79.0)$ \\
\hline \multicolumn{5}{|c|}{ Maternal height (cm) } \\
\hline$\leq 149$ & $68(7.5)$ & $66(7.4)$ & $47(6.9)$ & $19(9.0)$ \\
\hline $150-155$ & $198(21.9)$ & $193(21.8)$ & $152(22.5)$ & $41(19.5)$ \\
\hline $156-160$ & $380(42.0)$ & $399(45.0)$ & $295(43.6)$ & $104(49.5)$ \\
\hline $161-164$ & $120(13.3)$ & $109(12.3)$ & $84(12.4)$ & $25(11.9)$ \\
\hline$\geq 165$ & $100(11.0)$ & $103(11.6)$ & $86(12.7)$ & $17(8.1)$ \\
\hline Missing & $39(4.3)$ & $18(2.0)$ & $13(1.9)$ & $4(1.9)$ \\
\hline \multicolumn{5}{|c|}{ Maternal body mass index } \\
\hline$<18.5$ & $63(7.0)$ & $52(5.9)$ & $34(5.0)$ & $18(8.6)$ \\
\hline 18.5 to $<25$ & $439(48.5)$ & $474(53.4)$ & $356(52.6)$ & $118(56.2)$ \\
\hline 25 to $<30$ & $245(27.1)$ & $231(26.0)$ & $184(27.2)$ & $47(22.4)$ \\
\hline 30 to $<35$ & $91(10.1)$ & $91(10.3)$ & $72(10.6)$ & $19(9.0)$ \\
\hline$\geq 35$ & $28(3.1)$ & $21(2.4)$ & $18(2.7)$ & $3(1.4)$ \\
\hline Missing & $39(4.3)$ & $17(1.9)$ & $13(1.9)$ & $5(2.4)$ \\
\hline \multicolumn{5}{|c|}{ Husband's occupation } \\
\hline Unemployed & $25(2.8)$ & $56(6.3)$ & $37(5.5)$ & $19(9.0)$ \\
\hline Non skill worker & $400(44.2)$ & $419(47.2)$ & $312(46.1)$ & $107(51.0)$ \\
\hline Skill worker & $91(10.1)$ & $70(7.9)$ & $58(8.6)$ & $12(5.7)$ \\
\hline Self-employed & $111(12.3)$ & $101(11.4)$ & $89(13.1)$ & $12(5.7)$ \\
\hline Farmer & 179 (19.8) & $163(18.4)$ & $123(18.2)$ & $40(19.0)$ \\
\hline Other & $95(10.5)$ & $69(7.8)$ & $52(7.7)$ & $17(78.1)$ \\
\hline Missing & $4(0.4)$ & $9(1.0)$ & $6(0.9)$ & $3(1.4)$ \\
\hline Unemployed & $25(2.8)$ & $56(6.3)$ & $37(5.5)$ & $19(9.0)$ \\
\hline \multicolumn{5}{|l|}{ Preterm delivery } \\
\hline Term & $850(93.9)$ & $798(90.0)$ & $616(91.0)$ & $182(86.7)$ \\
\hline Preterm & $55(6.1)$ & $89(10.0)$ & $61(9.0)$ & $28(13.3)$ \\
\hline \multicolumn{5}{|l|}{ Infant sex } \\
\hline Female & $447(49.4)$ & $436(49.2)$ & $337(49.8)$ & 99 (47.1) \\
\hline Male & $443(49.0)$ & $441(49.7)$ & $331(48.9)$ & $110(52.4)$ \\
\hline Missing & $15(1.7)$ & $10(1.1)$ & $9(1.3)$ & $1(0.5)$ \\
\hline \multicolumn{5}{|l|}{ Birth weight (gr) } \\
\hline$\leq 2500$ & $43(4.8)$ & $99(11.2)$ & 75 (11.1) & $24(11.4)$ \\
\hline
\end{tabular}


Table 1 Characteristics of study subjects (Continued)

\begin{tabular}{|c|c|c|c|c|}
\hline & Unexposed $^{a}$ & Opium use & & \\
\hline & & All & Opium user only & Tobacco and Opium user \\
\hline & $N(\%)$ & $N(\%)$ & $N(\%)$ & $N(\%)$ \\
\hline 2500-2999 & $139(15.4)$ & $179(20.2)$ & $134(19.8)$ & $45(21.4)$ \\
\hline $3000-3299$ & $205(22.7)$ & $203(22.9)$ & $143(21.1)$ & $60(28.6)$ \\
\hline 3300-3599 & $269(29.7)$ & $193(21.8)$ & $154(22.7)$ & 39 (18.6) \\
\hline$\geq 3600$ & $234(25.9)$ & $203(22.9)$ & $162(23.9)$ & $41(19.5)$ \\
\hline Missing & $15(1.7)$ & $10(1.1)$ & $9(1.3)$ & $1(0.5)$ \\
\hline Birth length (cn & & & & \\
\hline$\leq 46$ & $59(6.5)$ & $115(13.0)$ & 87 (12.9) & $28(13.3)$ \\
\hline $47-48$ & $149(16.5)$ & $138(15.6)$ & $103(15.2)$ & $35(16.7)$ \\
\hline $49-51$ & $535(59.1)$ & $480(54.1)$ & $359(53.0)$ & $121(57.6)$ \\
\hline$\geq 52$ & $147(16.2)$ & $144(16.2)$ & $119(17.6)$ & $25(11.9)$ \\
\hline Missing & $15(1.7)$ & $10(1.1)$ & $9(1.3)$ & $1(0.5)$ \\
\hline Head circumfer & & & & \\
\hline$\leq 32$ & $56(6.2)$ & $119(13.4)$ & $88(13.0)$ & $31(14.8)$ \\
\hline $33-34$ & $242(16.7)$ & $337(38.0)$ & $252(37.2)$ & $85(40 . .5)$ \\
\hline $35-36$ & $476(52.6)$ & $362(40.8)$ & $281(41.5)$ & 81 (38.6) \\
\hline$\geq 37$ & $116(12.8)$ & $59(6.7)$ & $47(6.9)$ & $12(5.7)$ \\
\hline Missing & $15(1.7)$ & $10(1.1)$ & $9(1.3)$ & $1(0.5)$ \\
\hline
\end{tabular}

${ }^{a}$ Unexposed includes mothers who are non-users of both opium and tobacco

while corresponding percentages for small head circumference $(<33 \mathrm{~cm})$ were $6.2 \%$ and $13.4 \%$, respectively (Table 1$)$.

Compared with non-use of opium and tobacco, use of opium during pregnancy was associated with a $69 \%$ increased risk of birth of an SGA infant after adjusting for potential confounders. The risk of SGA was slightly higher in offspring of mothers who only used opium $(\mathrm{RR}=1.71$ and $95 \% \mathrm{CI} ; 1.34-2.18)$ than in offspring of mothers who both used opium and smoked tobacco during pregnancy $(\mathrm{R}=1.62$ and $95 \% \mathrm{CI}$; 1.13-2.30). Meanwhile, when we restricted the analysis into the term pregnancies, the risk of SGA was almost identical in offspring of mothers who only used opium $(\mathrm{RR}=1.58$ and 95\% CI; 1.22-2. 04), and offspring of dual user mothers $(\mathrm{RR}=1.58$ and 95\% CI; 1.09-2.29) (Table 2).

Compared with prenatally unexposed term infants, term infants who were prenatally exposed to opium had a more than doubled risk of short birth length $(<47 \mathrm{~cm})$. The risk of short birth length was essentially similar between those exposed to only opium $(R R=2.00$ and 95\% CI; 1.37-2.92) and those exposed to both opium and tobacco during pregnancy $(\mathrm{OR}=2.40$ and $95 \% \mathrm{CI}$; 1.20-3.48) (Table 3).

Compared with prenatally unexposed term infants, term infants who were prenatally exposed to opium had a 2.2-fold risk of the small head circumference at birth. The risk of a small head circumference was similar in infants prenatally exposed to only opium and in infants exposed to both opium and tobacco (Table 4).

\section{Discussion}

This cohort study revealed an increased risk of SGA at birth among offspring of mothers who used opium during pregnancy. This study showed that prenatal opium exposure also increased the risks of a short birth length and a small head circumference in infants born at term.

Our findings are consistent and extend results of previous studies showing that infants of mothers using heroin, methadone, or other opiates during pregnancy intend to have a higher risk of low birth weight $[14,15]$. Meta-analyses have shown that use of any kind of opiates during pregnancy is associated with a three-fold increased risk of perinatal mortality and a four-fold increased risk of low birth weight [16]. We found that infants prenatally exposed to opium were at increased risk of being born SGA, but the risk of SGA was similar among infants only prenatally exposed to opium and those exposed to both opium and tobacco. As maternal smoking is causally associated with fetal growth restriction, we expected a higher risk among infants exposed to both opium and tobacco [17]. We cannot explain the lack of additive effect of opium and tobacco on SGA. Residual confounding may be one possibility, but the lack of observed effect may also be due to chance [17]. 
Table 2 Risk ratios (RR) and 95\% confidence intervals (Cl) for the associations between opium and tobacco use during pregnancy and risk of small for gestational age at birth

\begin{tabular}{|c|c|c|c|c|}
\hline & Pregnancies & Small for gestational age ${ }^{a}$ & Crude & Adjusted $^{\mathrm{b}}$ \\
\hline & $N$ & $N(\%)$ & RR $(95 \% \mathrm{Cl})$ & RR $(95 \% \mathrm{Cl})$ \\
\hline \multicolumn{5}{|l|}{ Opium } \\
\hline Unexposed & 905 & $99(10.9)$ & Reference & \\
\hline Exposed & 887 & $154(17.4)$ & $1.59(1.26-1.99)$ & $1.69(1.34-2.13)$ \\
\hline \multicolumn{5}{|l|}{ Tobacco and opium } \\
\hline Unexposed & 905 & $99(10.9)$ & Reference & \\
\hline Exposed to opium only & 677 & $115(17.0)$ & $1.59(1.22-2.06)$ & $1.71(1.34-2.18)$ \\
\hline Exposed to tobacco and opium & 210 & 39 (18.6) & $1.58(1.10-2.28)$ & $1.62(1.13-2.30)$ \\
\hline \multicolumn{5}{|l|}{ Restricted to term pregnancies } \\
\hline \multicolumn{5}{|l|}{ Opium } \\
\hline Unexposed & 850 & $93(10.9)$ & Reference & \\
\hline Exposed & 798 & $132(16.5)$ & $1.46(1.15-1.86)$ & $1.58(1.23-2.02)$ \\
\hline \multicolumn{5}{|l|}{ Tobacco and opium } \\
\hline Unexposed & 850 & $93(10.9)$ & Reference & \\
\hline Exposed to opium only & 616 & $97(15.7)$ & $1.43(1.11-1.85)$ & $1.58(1.22-2.04)$ \\
\hline Exposed to tobacco and opium & 182 & $35(19.2)$ & $1.57(1.10-2.24)$ & $1.58(1.09-2.29)$ \\
\hline
\end{tabular}

${ }^{a}$ Small for gestational age was defined as a birth weight below the 10th percentile for appropriate gestational age, based on a sex-specific global reference for birth weight [13]

${ }^{\mathrm{b}}$ Adjusted for: maternal age, height, BMI, parity, husband's occupation, and residential place

Our study demonstrated that term infants who were exposed to opium had shorter birth length after adjusting for gestational age, sex and other potential confounders. An increased risk of a short birth length was also observed in studies investigating maternal heroin or methadone use during pregnancy [18]. Liu et al. reported that infants who

Table 3 Risk ratios (RR) and 95\% confidence intervals (Cl) for the associations between opium and tobacco use during pregnancy and risk of short birth length at term birth

\begin{tabular}{llll}
\hline Pregnancies & $\begin{array}{l}\text { Short } \\
\text { birth length }{ }^{\text {a }}\end{array}$ & Crude & Adjusted $^{b}$ \\
$N$ & $N(\%)$ & RR (95\% Cl) & RR (95\% \\
& & & Cl) \\
\hline
\end{tabular}

Opium

$\begin{array}{lllll}\text { Unexposed } & 850 & 50(5.9) & \text { Reference } & \\ \text { Exposed } & 798 & 92(11.5) & 1.95(1.38-2.75) & 2.01 \\ & & & & (1.40-2.89)\end{array}$

Tobacco and

opium

$\begin{array}{llll}\text { Unexposed } & 850 & 50(5.9) & \text { Reference } \\ \begin{array}{l}\text { Exposed to } \\ \text { opium only }\end{array} & 70(11.4) & 1.93(1.36-2.73) & 2.00 \\ \begin{array}{l}\text { Exposed to } \\ \text { tobacco }\end{array} & & & (1.37-2.92) \\ \text { and opium } & 22(12.2) & 2.03(1.26-3.27) & 2.04 \\ & & & (1.20-3.48) \\ \end{array}$

${ }^{a}$ Birth length less than $47 \mathrm{~cm}$ (below the 5th percentile of birth length of unexposed and term live birth)

${ }^{\mathrm{b}}$ Adjusted for: maternal age, height, BMI, parity, weeks gestational age, infant sex, husband's occupation, and residential place were prenatally exposed to opium or methadone had shorter birth length compared with unexposed infants [15]. An ultrasonic investigation during pregnancy showed that fetuses exposed to opiates had shorter femur and humerus lengths compared with unexposed fetus [19].

In this study, we also found that opium exposure during pregnancy is associated with a reduced head circumference, which is consistent with results of previous studies on maternal heroin or methadone use during pregnancy [15]. Hunt et al. reported that neonates prenatally exposed to opiates on average had smaller head circumference at birth. However, the study included both term and preterm infants, and the exposed group were born at a lower gestational age than the unexposed group [20]. A Swiss study also documented a four-fold increased risk of the small head circumference at birth (smaller than the third percentile) among neonates of methadone-addicted mothers [21]. Previous studies reported children of mothers using opiate during pregnancy had higher risks of intentional disorders, impaired motors, and cognitive functions, at school ages which could be due to impaired neurodevelopment [20, 22]. The long-term effects of opium exposure in utero on psycho-behavioral dysfunctions in offspring have also been demonstrated in other studies [23].

Several explanations have been proposed for the associations of opiates exposures during pregnancy with risks of fetal brain development and growth restrictions. Using opiate during pregnancy is associated with risks of preeclampsia, premature labor, premature rupture of 
Table 4 Risk ratios (RR) and 95\% confidence intervals (Cl) for the associations between opium and tobacco use during pregnancy and risk of small head circumference at term birth

\begin{tabular}{|c|c|c|c|c|}
\hline & Pregnancies & Small head circumference ${ }^{a}$ & Crude & Adjusted $^{\mathrm{b}}$ \\
\hline & N & $N(\%)$ & RR $(95 \% \mathrm{Cl})$ & RR $(95 \% \mathrm{Cl})$ \\
\hline \multicolumn{5}{|l|}{ Opium } \\
\hline Unexposed & 850 & $45(5.3)$ & Reference & \\
\hline Exposed & 798 & $99(12.4)$ & $2.33(1.64-3.32)$ & $2.24(1.55-3.24)$ \\
\hline \multicolumn{5}{|l|}{ Tobacco and opium } \\
\hline Unexposed & 850 & $45(5.3)$ & Reference & \\
\hline Exposed to opium only & 616 & $76(12.3)$ & $2.33(1.61-3.36)$ & $2.24(1.53-3.29)$ \\
\hline Exposed to tobacco and opium & 182 & $23(12.6)$ & $2.36(1.43-3.90)$ & $2.23(1.31-3.79)$ \\
\hline
\end{tabular}

${ }^{\mathrm{a} S m a l l}$ head circumference less than $33 \mathrm{~cm}$ (below the 5 th percentile of head circumference of unexposed and term live birth)

${ }^{\mathrm{b}}$ Adjusted for: maternal age, height, BMI, parity, husband's occupation, infant sex, weeks gestational age, and residential place

membranes, placental abruption, placental insufficiency and intrauterine death [24]. Maternal narcotic use induces hypoxia and asphyxia in the fetus, which is a consequence of fluctuating overdose-withdrawal cycles during pregnancy [25]. Moreover, animal studies showed a direct effect of opiates on the neural elements of the fetus [26]. It has also been suggested that factors such as parental psychopathology, maternal multiple drug abuse, poor prenatal care, dietary restriction, and disadvantaged socioeconomic circumstances could mediate associations between opiates exposures during pregnancy and risks of fetal brain development and growth restriction [27]. However, Pinto et al. reported that despite comprehensive antenatal care, drug-using women are at higher risk of giving birth to a low birth weight infant [5].

Opium has traditionally been used in southern Asia and middle-eastern countries such as Iran as a sedative and for pleasure. It has been shown that opium users have less psychiatric comorbidity, unemployment, homelessness, and criminal behavior compared with users of other narcotic drugs $[10,28]$. In Iran, the socioeconomic profile of opium users was almost identical with the socioeconomic circumstance of the general population [8]. In rural areas of Golestan province, where most of them are housewives, their pregnancies are planned, and approximately $97 \%$ of all pregnant women have access to primary health service funded by the state [29].

Strengths of this study include the cohort design, using prospectively collected information from antenatal visits before and during pregnancy. The population was relatively homogeneous, and opium-exposed mothers had otherwise had a normal lifestyle and an acceptable level of care during pregnancy [10]. We excluded a small proportion of women who were exposed to alcohol and selected non-users of opium and tobacco as the reference group to increase internal validity. Potential limitations include a lack of detailed information on mothers' socioeconomic circumstances. However, we controlled for husband's occupation and region of residence. Information on exposure to opium and smoking during pregnancy was based on self-reports during routine visits. There was no information on the frequency or dose of opium to estimate dose-response associations. If mothers did not report their drug use, this may have pushed our estimates toward the null. However, the reliability of self-reported opium use in rural Golestan has been reported as high [30]. Gestational age was estimated based on information on the first day of the last maternal menstrual period, which can be subject to error [31]. Finally, as the study was based on data on pregnancies in the rural area of Golestan province, there may be concern regarding the generalizability of the results.

\section{Conclusions}

Maternal opium use during pregnancy is associated with giving birth to small for gestational age infants, and with short birth length and small head circumference in term infants. It is unlikely that the observed associations are confounded by other factors related to high-risk behavior, such as the use of other harmful substances. Preventative intervention studies should be conducted in regions where opium use is common among young women.

\section{Abbreviations \\ BMI: Body Mass Index; Cls: Confidence Intervals; cm: centimeter; RRs: Risk Ratios; SGA: Small for Gestational Age}

\section{Acknowledgments}

We are indebted to the members of the primary health care system of Golestan University of medical sciences, particularly maternal health care units in the rural area of Golestan north of Iran. We value the administrative contribution of Dr. Mohammad Na'imi M.D., Mph, and Mr. Abbas

Moghadami MSc, (both at Golestan University of medical sciences).

Funding

This work was entirely funded by internal funding of Karolinska Institute.

Availability of data and materials

The contact person for requesting this dataset in Karolinska Institutet is Associate Professor Shahram Bahmanyar (Shahram.Bahmanyar@ki.se; Department of Medicine, Solna). The ethical permission for this study is limited to the previously defined study plan and making individual data available to the public is beyond the ethical permission. However, all 
information could be available after achieving permission from the local Ethical Committee.

\section{Authors' contributions}

SC and SB planned and designed the study. SMaghsoudlou, SB, MA, and SS contributed in the data collection and provided access to the data. SMaghsoudlou, SC, and SB involved in the review of the raw data and directly involved in the analysis. SC, SB, SMontgomery, and AW supervised this process and provided analytical feedback based on aggregated results. SMaghsoudlou, SC, MA, SMontgomery, AW, and SB involved directly in interpreting the results, and substantively reviewed and commented on the multiple drafts. SMaghsoudlou drafted and wrote the manuscript. All authors read and approved the final manuscript.

\section{Ethics approval and consent to participate}

The study was a secondary analysis of data. Only anonymous aggregated data were analyzed and presented in the final results. Ethical committees of Golestan University of medical sciences, Iran (35/2633-p/g, 17 January 2011) and Karolinska Institutet, Sweden (2011/1657-31/3) approved the study prior to commencement.

\section{Consent for publication}

Not applicable.

\section{Competing interests}

All authors declare that they have no competing interests.

\section{Publisher's Note}

Springer Nature remains neutral with regard to jurisdictional claims in published maps and institutional affiliations.

\section{Author details}

${ }^{1}$ Clinical Epidemiology Unit, Department of Medicine, Karolinska Institute, Solna, Sweden. ${ }^{2}$ Department of Obstetrics \& Gynecology, McMaster University, 1280 Main Street West, room 3N52F, Hamilton, ON L8S 4K1, Canada. ${ }^{3}$ Clinical Epidemiology and Biostatistics, School of Medical Sciences, Örebro University, Örebro, Sweden. ${ }^{4}$ Department of Epidemiology and Public Health, University College London, London, UK. ${ }^{5}$ Faculty of Medicine, Mazandaran University of Medical Sciences, Sari, Iran. 'Faculty of Medicine, Golestan University of Medical Sciences, Gorgan, Iran. ${ }^{7}$ Department of Clinical Sciences, Karolinska Institute, Danderyd Hospital, Stockholm, Sweden. ${ }^{8}$ Clinical Epidemiology Unit \& Centre for Pharmacoepidemiology, Department of Medicine, Karolinska Institute, Solna, Sweden.

\section{Received: 15 March 2017 Accepted: 24 August 2018}

\section{Published online: 01 October 2018}

\section{References}

1. Fischer B, Jones W, Rehm J. Trends and changes in prescription opioid analgesic dispensing in Canada 2005-2012: An update with a focus on recent interventions. BMC Health Serv Res. 2014;14:90. Available from: https://www.ncbi.nlm.nih.gov/pmc/articles/PMC3941687/.

2. Knoppert D. The worldwide opioid epidemic: Implications for treatment and research in pregnancy and the newborn. Pediatr Drugs. 2011;13:277-9.

3. Macaleer B, Shannon J. Does HR planning improve business performance. Ind Manag. 2003;45(1):14

4. Brunton LL, Knollmann BC, Hilal-Dandan R. Goodman \& Gilman's the pharmacological basis of therapeutics [Internet]. Thirteenth. New York: McGraw Hill Medical; 2018. Available from: https://accessmedicine. mhmedical.com/book.aspx?bookid=2189.

5. Pinto SM, Dodd S, Walkinshaw SA, Siney C, Kakkar P, Mousa HA. Substance abuse during pregnancy: effect on pregnancy outcomes. Eur J Obstet Gynecol Reprod Biol. 2010;150:137-41. Available from: https://www.ejog. org/article/S0301-2115(10)00092-8/fulltext. Accessed 22 Aug 2017.

6. Bandstra ES, Morrow CE, Mansoor E, Accornero VH. Prenatal drug exposure: Infant and toddler outcomes. J Addict Dis. 2010;29:245-58. Available from: http://www.tandfonline.com/doi/abs/10.1080/10550881003684871.

7. Keegan J, Parva M, Finnegan M, Gerson A, Belden M. Addiction in pregnancy. J Addict Dis. 2010;29:175-91. Available from: http://www. tandfonline.com/doi/abs/10.1080/10550881003684723.
8. Khademi H, Malekzadeh R, Pourshams A, Jafari E, Salahi R, Semnani S, et al. Opium use and mortality in Golestan cohort study: prospective cohort study of 50,000 adults in Iran. BMJ. 2012;344:e2502. Available from: http:// www.bmj.com/cgi/doi/10.1136/bmj.e2502.

9. Maghsoudlou S, Cnattingius S, Aarabi M, Montgomery SM, Semnani S, Stephansson $\mathrm{O}$, et al. Consanguineous marriage, prepregnancy maternal characteristics and stillbirth risk: A population-based case-control study. Acta Obstet Gynecol Scand. 2015;94:1095-1101. Available from: https://doi.org/10. 1111/aogs.12699. [Accessed 7 Feb 2017]

10. Rahimi-Movaghar A, Hefazi M, Davoli M, Amato L, Amin-Esmaeili M, Yousefi-Nooraie R. Pharmacological therapies for maintenance treatments of opium dependency. Cochrane Database Syst Rev. 2009; https://www. cochranelibrary.com/cdsr/doi/10.1002/14651858.CD007775.pub2/full.

11. Maghsoudlou S, Cnattingius S, Montgomery S, Aarabi M, Semnani S, Wikström AK, et al. Opium use during pregnancy and risk of preterm delivery: A population-based cohort study. PLoS One. 2017;12:1-11. Available from: https://journals.plos.org/plosone/article?id=10.1371/journal. pone.0176588. https://doi.org/10.1371/journal.pone.0176588.

12. Malekzadeh MM, Khademi H, Pourshams A, Etemadi A, Poustchi H, Bagheri $\mathrm{M}$, et al. Opium Use and Risk of Mortality from Digestive Diseases: A Prospective Cohort Study. Am J Gastroenterol. 2013;108:1757-65. Available from: http://www.nature.com/doifinder/10.1038/ajg.2013.336.

13. Mikolajczyk RT, Zhang J, Betran AP, Souza JP, Mori R, Gülmezoglu AM, et al. A global reference for fetal-weight and birthweight percentiles. Lancet. 2011:377:1855-61.

14. Patel P, Abdel-Latif ME, Hazelton B, Wodak A, Chen J, Emsley F, et al. Perinatal outcomes of Australian buprenorphine-exposed mothers and their newborn infants. J Paediatr Child Health. 2013:49:746-53.

15. Liu AJW, Sithamparanathan S, Jones MP, Cook CM, Nanan R. Growth restriction in pregnancies of opioid-dependent mothers. Arch Dis Child Fetal Neonatal Ed. 2010;95:F258-62. Available from: http://fn.bmj.com/cgi/ doi/10.1136/adc.2009.163105.

16. Hulse GK, Milne E, English DR, Holman CD. The relationship between maternal use of heroin and methadone and infant birth weight. Addiction. 1997;92: 1571-9. Available from: http://www.ncbi.nlm.nih.gov/pubmed/9519499.

17. Cnattingius S. The epidemiology of smoking during pregnancy: Smoking prevalence, maternal characteristics, and pregnancy outcomes. Nicotine Tob. Res. 2004;6:125-40. Available from: https://doi.org/10.1080/ 14622200410001669187.

18. Minnes S, Lang A, Singer L. Prenatal tobacco, marijuana, stimulant, and opiate exposure: outcomes and practice implications. Addict Sci Clin Pract. 2011;6:57-70. Available from: https://www.ncbi.nlm.nih.gov/pubmed/ 22003423

19. Visconti K, Hennessy K, Towers C, Hennessy M, Howard B. 128: opiate abuse/usage in pregnancy and newborn head circumference. Am J Obstet Gynecol. 2013;208:S67-8. Available from: https://www.ajog.org/article/S00029378(12)01376-2/fulltext.

20. Hunt RW, Tzioumi D, Collins E, Jeffrey HE. Adverse neurdevelomental outcome of infants exposed to opiate in-utero. Early Hum Dev. 2008; 84:29-35.

21. Kashiwagi M, Arlettaz R, Lauper U, Zimmermann R, Hebisch G. Methadone maintenance program in a Swiss perinatal center: (I): management and outcome of 89 pregnancies. Acta Obstet Gynecol Scand. 2005:84:140-4

22. Ranke MB, Krägeloh-Mann I, Vollmer B. Growth, head growth, and neurocognitive outcome in children born very preterm: methodological aspects and selected results. Dev Med Child Neurol. 2015;57:23-8.

23. Lester BM, Bagner DM, Liu J, LaGasse LL, Seifer R, Bauer CR, et al. Infant neurobehavioral dysregulation: behavior problems in children with prenatal substance exposure. Pediatrics. 2009;124:1355-62. Available from: http:// pediatrics.aappublications.org/cgi/doi/10.1542/peds.2008-2898.

24. Kaltenbach K, Berghella V, Finnegan L. Opioid dependence during pregnancy: effects and management. Obstet Gynecol Clin North Am. 1998;25:139-51. Available from: http://www.sciencedirect.com/science/article/pii/ S0889854505703624.

25. Kuczkowski KM. Anesthetic implications of drug abuse in pregnancy. J Clin Anesth. 2003;15:382-94.

26. Sakellaridis N, Mangoura D, Vernadakis A. Effects of opiates on the growth of neuron-enriched cultures from chick embryonic brain. Int J Dev Neurosci. 1986;4:293-302.

27. Cengiz H, Daǧdeviren $\mathrm{H}$, Karaahmet $\mathrm{O}$, Kaya C, Yildiz S, Ekin M. Maternal and neonatal effects of substance abuse during pregnancy: a case report. Haseki 
Tip Bul. 2013;51:76-8. Available from: http://www.hasekidergisi.com/ archives/archive-detail/article-preview/maternal-and-neonatal-effects-ofsubstance-abuse-d/6200.

28. Ghaffari Nejad A, Ziaadini H, Banazadeh N. Comparative Evaluation of Psychiatric Disorders in Opium and Heroin Dependent PatientstThis article has been published in the Journal of Rafsanjan University of Medical Sciences in Persian language. Addict Heal. 2009;1:20-3. Available from: https://www.ncbi.nlm.nih.gov/pmc/articles/PMC3905498/.

29. Rashidian A, Khosravi A, Khabiri R, Khodayari-Moez E, Elahi E, Arab M, et al. Islamic Republic of Iran's Multiple Indicator Demograpphic and Healh Survey (IrMIDHS) 2010. IrMIDHS. 2012;

30. Abnet CC, Saadatian-Elahi M, Pourshams A, Boffetta P, Feizzadeh A, Brennan $P$, et al. Reliability and validity of opiate use self-report in a population at high risk for esophageal cancer in Golestan, Iran. Cancer Epidemiol. Biomarkers Prev. AACR. 2004;13:1068-70.

31. Kramer MS, Platt RW, Yang H, Haglund B, Cnattingius S, Bergsjo P. Registration Artifacts in International Comparisons of Infant Mortality. Obstet Gynecol Surv. 2002;57:429-30. Available from: https://onlinelibrary.wiley. com/doi/abs/10.1046/j.1365-3016.2002.00390.x

Ready to submit your research? Choose BMC and benefit from:

- fast, convenient online submission

- thorough peer review by experienced researchers in your field

- rapid publication on acceptance

- support for research data, including large and complex data types

- gold Open Access which fosters wider collaboration and increased citations

- maximum visibility for your research: over $100 \mathrm{M}$ website views per year

At $\mathrm{BMC}$, research is always in progress.

Learn more biomedcentral.com/submissions 